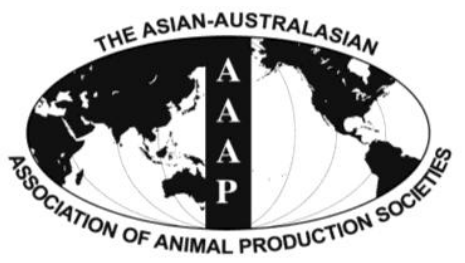

Asian-Aust. J. Anim. Sci.

Vol. 26, No. 2 : 163-170 February 2013

http://dx.doi.org/10.5713/ajas.2012.12499

www.ajas.info

pISSN 1011-2367 elSSN 1976-5517

\title{
mtDNA Diversity and Phylogenetic State of Korean Cattle Breed, Chikso
}

\author{
Jae-Hwan Kim*, Mi Jeong Byun, Myung-Jick Kim, Sang Won Suh, Yeoung-Gyu Ko, \\ Chang Woo Lee ${ }^{1}$, Kyoung-Sub Jung², Eun Sung Kim³, Dae Jung Yu, \\ Woo Hyun Kim ${ }^{5}$ and Seong-Bok Choi \\ Animal Genetic Resources Station, National Institute of Animal Science, RDA, Namwon 590-832, Korea
}

\begin{abstract}
In order to analyze the genetic diversity and phylogenetic status of the Korean Chikso breed, we determined sequences of mtDNA cytochrome $\mathrm{b}$ (cyt $b$ ) gene and performed phylogenetic analysis using 239 individuals from 5 Chikso populations. Five nonsynonymous mutations of a total of 15 polymorphic sites were identified among 239 cyt $b$ coding sequences. Thirteen haplotypes were defined, and haplotype diversity was 0.4709 ranging from 0.2577 to 0.6114 . Thirty-five haplotypes (C1-C35) were classified among 9 Asia and 3 European breeds. C2 was a major haplotype that contained 206 sequences (64.6\%) from all breeds used. C3-C13 haplotypes were Chikso-specific haplotypes. $\mathrm{C} 1$ and $\mathrm{C} 2$ haplotypes contained $80.5 \%$ of cyt $b$ sequences of Hanwoo, Yanbian, Zaosheng and JB breeds. In phylogenetic analyses, the Chikso breed was contained into B. taurus lineage and was genetically more closely related to two Chinese breeds than to Korean brown cattle, Hanwoo. These results suggest that Chikso and Hanwoo have a genetic difference based on the mtDNA cyt $b$ gene as well as their coat color, sufficient for classification as a separate breed. (Key Words: Phylogenetic Analysis, Chikso, Haplotype, mtDNA, Cytochrome $b$ )
\end{abstract}

\section{INTRODUCTION}

The now-extinct aurochs (Bos primigenius), which ranged throughout much of Eurasia and Northern Africa, is widely accepted as the wild ancestor of modern domesticated cattle (MacHugh et al., 1998). Archaeological evidence shows that domestication of this animal occurred independently in the near East and in the Indian subcontinent between 10,000 to $8,000 \mathrm{yrs}$ ago, giving rise to the two taxa of domestic cattle, namely $B$. taurus and B. indicus (Helmer et al., 2005; Bradley and Magee, 2006).

\footnotetext{
* Corresponding Author: Jae-Hwan Kim. Tel: +82-63-620-3522, Fax: +82-63-620-3590, E-mail: jkim3892@korea.kr

${ }^{1}$ Gangwon Provincial Livestock Research Center, Hoengseong, Gangwon 225-831, Korea.

2 Chungbuk Institute of Livestock and Veterinary Research, Cheongwon, Chungbuk 363-931, Korea.

${ }^{3}$ Jeonbuk Institute of Livestock and Veterinary Research, Gimje, Jeonbuk 576-882, Korea.

4 Jeonnam Agricultural Research and Extension Services, Gangjin, Jeonnam 527-822, Korea.

${ }^{5}$ Gyeongbuk Livestock Research Institute, Yeongju, Gyeongbuk 750-871, Korea.

Submitted Sept. 11, 2012; Accepted Oct. 11, 2012; Revised Nov. 19, 2012
}

Genetic diversity of animal genetic resources (AnGR) compensates for changing environmental conditions, including climate, markets, and disease etc. Because AnGR are likely to continue to change and adapt in the future (Bruford et al., 2003; Toro and Caballero, 2005), the maintaining of their genetic diversity is important and essential for future use. However, during the last century, many indigenous domestic breeds became extinct by replacement or crossbreeding with exotic productive breeds. Therefore, the Food and Agriculture Organization of the United Nations (FAO) has encouraged a series of conservation measures designed to help prevent irreversible loss of domestic animal species (FAO, 2007b). In addition, conservation is one of the four Strategic Priority Areas of the recently adopted Global Plan of Action for AnGR (FAO, 2007a).

Molecular genetic studies within and across breeds are essential for the effective management of AnGR (Hall and Bradley, 1995; Ruane, 2000; Simianer, 2005). Mammalian mitochondrial DNA (mtDNA) shows several special features such as an absence of intron, maternal inheritance, the existence of single copy orthologous genes, lack of recombination events and a high mutation rate (Irwin et al., 
1991; Pesole et al., 1999). Since the complete sequence of bovine mtDNA was published (Anderson et al., 1982), mtDNA have been widely used for genetic diversity and phylogenetic analysis among different cattle breeds (Bradley et al., 1996; Troy et al., 2001; Kikkawa et al., 2003; Kim et al., 2003; Berthouly et al., 2010; MartínBurriel et al., 2011). Especially mtDNA cytochrome b (cyt $b$ ) has been broadly determined for the description of phylogenetic states of several species (Lau et al., 1998; Sultana et al., 2003; Souza et al., 2009; Stock et al., 2009; Yap et al., 2010).

More than 3,000 breeds of cattle are widely distributed throughout the world based on a Domestic Animal Diversity Information System (DAD-IS) from the FAO (http://dad.fao.org/). Four indigenous Korean cattle breeds are listed in the DAD-IS, and of them, the Chikso breed is an endangered breed with a unique brindle coat color. Efforts towards their conservation and proliferation have been made by government, universities and farmers. However, the genetic diversity, origin and evolution of this cattle breed have not been elucidated. The purposes of this investigation are to determine sequences of the mtDNA cyt $b$ gene in full length, and to verify the genetic diversity, maternal origins and phylogenetic relationships of the Chikso breed.

\section{MATERIALS AND METHODS}

\section{Sample collection and DNA extraction}

The national management for the Chikso breed is carried out by 7 local institutions for AnGR management. The 239 blood samples were obtained from 5 institutions (Table 1) and were stored at $-70^{\circ} \mathrm{C}$ until further processing. Genomic DNA was extracted from blood following an established protocol (Miller et al., 1988). The concentration of extracted DNA was measured using NanoDrop ND1000 (Thermo Scientific, USA), and was diluted to use as template for amplification.

\section{Amplification and sequencing}

The complete cyt $b$ gene was amplified by using forward primer Bcyt-F: 5'-TTCTTACATGGAATCT AACCATGA-3' and reverse primer Bcyt-R: 5'-
GGGAGGTTAGTTGTTCTCCTTCTC-3'. The forward and reverse primers were designed from tRNA-Glu and tRNA-Thr sequences of the mtDNA genome (GenBank accession no. V00654). Polymerase chain reaction (PCR) was carried out in a total volume of $25 \mu \mathrm{l}$, containing $10 \mathrm{ng}$ of genomic DNA, $2.5 \mu$ of $10 \times$ buffer, $0.2 \mathrm{mM}$ of dNTP, 10 $\mathrm{pM}$ of each primer and 1.5 units of Taq polymerase (TaKaRa, Japan). Thermal cycling was performed on a PTC-200 thermocycler (MJ Research Inc.) under the following conditions; 2 min denaturation at $94^{\circ} \mathrm{C}$, followed by 35 cycles of $30 \mathrm{~s}$ at $94^{\circ} \mathrm{C}, 30 \mathrm{~s}$ at $60^{\circ} \mathrm{C}, 60 \mathrm{~s}$ at $72^{\circ} \mathrm{C}$, and a final $5 \mathrm{~min}$ at $72^{\circ} \mathrm{C}$ before cooling to $4^{\circ} \mathrm{C}$ for $10 \mathrm{~min}$. The amplified products were separated by electrophoresis on $1.2 \%$ agarose gels, and were visualized under UV illumination after staining with ethidium bromide. The PCR products were purified using a QIAquick PCR purification Kit (Qiagen, USA), and were directly sequenced on an ABI 3130xl Genetic Analyzer (PE Applied Biosystems, USA). The boundaries of the cyt $b$ gene were determined by comparison with the $B$. taurus mtDNA genome sequence (GenBank accession no. V00654) as reported by Anderson et al. (1982).

\section{Statistical and phylogenetic analyses}

The sequences of the cyt $b$ gene from different breeds were aligned in CLUSTAL W (Thompson et al., 1994). Numbers of nucleotide polymorphic sites (S) and haplotype (h), nucleotide diversity (Pi), haplotype diversity ( $\mathrm{Hd})$ and nucleotide divergence (Dxy) were performed in DNA sequence polymorphism Version 5.1 (Librado and Rozas, 2009). The Neighbor-joining (NJ) tree (Saitou and Nei, 1987) among haplotypes based on the cyt $b$ gene sequences was reconstructed in MEGA 5.05 package (Tamura et al., 2011), with the reliability of the tree topology assessed by 1,000 bootstrap replications (Felsenstein, 1985). The NJ tree among breeds was constructed in MEGA 5.05 package on the basis of Dxy distances.

\section{RESULTS AND DISCUSSION}

\section{Sequence composition and variation of the cyt $\boldsymbol{b}$ gene}

The full-length coding sequences of the cyt $b$ genes in

Table 1. Number of polymorphic sites (S), number of haplotypes (h), haplotype diversity (Hd) and nucleotide diversity (Pi) within 5 Chikso populations

\begin{tabular}{llrrrrr}
\hline Populations & \multicolumn{1}{c}{ Institutions } & Sample sizes & $\mathrm{S}$ & $\mathrm{h}$ & $\mathrm{Hd}$ & $\mathrm{Pi}$ \\
\hline GAN & Gangwon Provincial Livestock Research Center & 54 & 1 & 2 & 0.2577 & 0.00023 \\
CHU & Chungbuk Institute of Livestock and Veterinary Research & 78 & 7 & 8 & 0.6114 & 0.00067 \\
JEOB & Jeonbuk Institute of Livestock and Veterinary Research & 54 & 7 & 5 & 0.3892 & 0.00066 \\
JEON & Jeonnam Agricultural Research and Extension Services & 18 & 1 & 2 & 0.4248 & 0.00037 \\
GYE & Gyeongbuk Livestock Research Institute & 35 & 6 & 7 & 0.5244 & 0.00057 \\
Total & & 239 & 15 & 13 & 0.4709 & 0.00055 \\
\hline
\end{tabular}


239 Chikso individuals were determined. All these sequences spanned $1,140 \mathrm{bp}$, started with an ATG translational start codon and ended with an AGA stop codon. No insertion/deletion or length variation was detected in these sequences. Compositional frequency of $\mathrm{G}$ base was the lowest $(13.4 \%)$ other 3 bases (A, 31.2\%; C, 30.2\%; T, $25.2 \%$ ). These patterns were very similar to those of a previous report which analyzed Chinese cattle breeds (Cai et al., 2007).

Fifteen polymorphic sites were identified among 239 cyt $b$ coding sequences (Figure 1). All polymorphic sites were transition mutations, but there was no transversion mutation. Among the 15 polymorphic sites, 2 of them (site positions: 329, 643) were variant-singleton variable sites, and the others were two variant parsimony informative sites. In addition, 5 non-synonymous mutations (A232G, T329C, G643A, G736A, and A1114G) were identified, and substitutions of amino acid by these mutations were estimated as I78V, L110P, V215M, A246T, and I372V, respectively.

Thirteen haplotypes were defined by polymorphisms at 15 sites, and the cyt $b$ sequences of these haplotypes were submitted to GenBank (Accession no. JX472262-74). The nucleotide diversity (Pi) of all individuals was 0.00055 and ranged from 0.00023 (GAN) to 0.00067 (CHU) (Table 1). Haplotype diversity $(\mathrm{Hd})$ of Chikso was 0.4709 and ranged from 0.2577 (GAN) to 0.6114 (CHU). The Pi and Hd of the Chikso breed is lower than those of Chinese breeds of taurine lineage (Cai et al., 2007).

\section{Haplotype distribution}

For verification of the haplotype distribution of Chikso among Asian and European breeds, we obtained the cyt $b$ gene sequences of Korean brown (called Hanwoo), Japanese black (JB), 6 Chinese breeds, and 3 European cattle breeds from GenBank database (Table 2). The distribution of the haplotypes in the Chikso and other
11

233566677889901 326124533152911 290013456324744

\begin{tabular}{|c|c|}
\hline $\mathrm{C} 1$ & ATGACGCCGGCCTTA \\
\hline $\mathrm{C} 2$ & $\ldots \ldots \ldots \ldots c$. \\
\hline $\mathrm{C} 3$ &.$C \ldots \ldots \ldots$ \\
\hline & $G \ldots \ldots \ldots$ C. \\
\hline & $\ldots \ldots$. . . C. \\
\hline & $\ldots \ldots \ldots$ A. C. \\
\hline & $\ldots G \ldots \ldots \ldots$ \\
\hline & $\ldots \ldots$. . T.C. \\
\hline & $\ldots \ldots \ldots \mathrm{TC}$ \\
\hline & $\ldots$ A.T..... C.G \\
\hline & $\ldots . .$. \\
\hline & $\ldots \ldots$. . . \\
\hline & $\ldots$ A. . \\
\hline
\end{tabular}

Figure 1. Sequence variation of 13 haplotypes (C1-C13) in the mtDNA cyt $b$ gene of 239 individuals of the Chikso breed. Mutations are scored relative to the reference sequence (GenBank accession no. DQ186215) of Cai et al. (2007). Dots (.) denote identity with sequence of the $\mathrm{C} 1$ haplotype.

breeds is shown in Table 3. Thirty five haplotypes (C1-C35) were classified from 319 cyt $b$ gene sequences. $\mathrm{C} 2$ was a major haplotype that contained 206 sequences (64.6\%) from all breeds used. $\mathrm{C} 1$ was the second largest haplotype that included 54 sequences (16.9\%). This haplotype did not contain any of the European breeds, nor did it contain 2 of the Chinese breeds (Kazakh and Jinnan). C3-C13 haplotypes were Chikso-specific haplotypes, and there were no other breeds that contained at these haplotypes. $\mathrm{C} 1$ and C2 haplotypes contained $80.5 \%$ of cyt $b$ sequences of Hanwoo, Yanbian, Zaosheng and JB breeds. Especially, all sequences of the Yanbian breed were contained at $\mathrm{C} 1$ and C2 haplotypes.

\section{Phylogenetic analysis of the cyt $b$ gene}

The neighbor-joining $(\mathrm{NJ})$ tree was constructed to verify

Table 2. Information on reference sequences for comparison with Chikso breed

\begin{tabular}{lllcl}
\hline Region & Abbreviation & Breed names & Number of sequences & Accession numbers \\
\hline Korean & Chi & Chikso & 239 & JX472262-74 (this study) \\
& KB & Korean brown & 18 & AY526085, DQ124371-86, NC_006853 \\
& Boh & Bohai black & 8 & AY885297-300, AY952962-3, DQ186227-8 \\
& Yan & Yanbian & 6 & AY903438, DQ186215-9 \\
& Zao & Zaosheng & 7 & DQ186220-6 \\
& Kaz & Kazakh & 11 & DQ186203-13 \\
Japan & Qin & Qinchuan & 8 & AY885304-6, AY903439, AY952952-3, DQ186241-2 \\
European & Jin & Jinnan & 8 & DQ186229-36 \\
& JB & Japanese Black & 7 & AB074962-8 \\
& Ang & Angus & 2 & AY676857, AY676859 \\
& Cha & Charolais & 2 & AY676858, AY676861 \\
& Lim & Limousine & 3 & AY676856, EF693798, JN817331 \\
\hline
\end{tabular}


Table 3. Distribution of mtDNA haplotypes in 12 cattle breeds based on cyt $b$ gene sequences

\begin{tabular}{|c|c|c|c|c|c|c|c|c|c|c|c|c|c|}
\hline \multirow{2}{*}{ Haplotype } & \multicolumn{12}{|c|}{ Cattle breed $*$} & \multirow{2}{*}{ Tota } \\
\hline & Chi & $\mathrm{KB}$ & Boh & Yan & Zao & $\mathrm{Kaz}$ & Qin & Jin & JB & Ang & Cha & Lim & \\
\hline $\mathrm{C} 1$ & 41 & 4 & 1 & 1 & 1 & & 1 & & 2 & & & & 51 \\
\hline $\mathrm{C} 2$ & 169 & 10 & 2 & 5 & 5 & 1 & 3 & 3 & 4 & 1 & 1 & 2 & 206 \\
\hline $\mathrm{C} 3$ & 1 & & & & & & & & & & & & 1 \\
\hline $\mathrm{C} 4$ & 4 & & & & & & & & & & & & 4 \\
\hline $\mathrm{C} 5$ & 2 & & & & & & & & & & & & 2 \\
\hline C6 & 5 & & & & & & & & & & & & 5 \\
\hline C7 & 4 & & & & & & & & & & & & 4 \\
\hline $\mathrm{C} 8$ & 2 & & & & & & & & & & & & 2 \\
\hline C9 & 2 & & & & & & & & & & & & 2 \\
\hline $\mathrm{C} 10$ & 3 & & & & & & & & & & & & 3 \\
\hline C11 & 3 & & & & & & & & & & & & 3 \\
\hline $\mathrm{C} 12$ & 2 & & & & & & & & & & & & 2 \\
\hline $\mathrm{C} 13$ & 1 & & & & & & & & & & & & 1 \\
\hline C14 & & 1 & & & & & & & & & & & 1 \\
\hline $\mathrm{C} 15$ & & 1 & & & & & & & & & & & 1 \\
\hline $\mathrm{C} 16$ & & 1 & & & & & & & & & & & 1 \\
\hline C17 & & 1 & & & & & & & & & & & 1 \\
\hline $\mathrm{C} 18$ & & & 1 & & & & & & & & & & 1 \\
\hline C19 & & & 3 & & & 1 & 2 & 3 & & & & & 9 \\
\hline $\mathrm{C} 20$ & & & 1 & & & & & & & & & & 1 \\
\hline $\mathrm{C} 21$ & & & & & 1 & & & & & & & & 1 \\
\hline $\mathrm{C} 22$ & & & & & & 3 & & & & & & & 3 \\
\hline $\mathrm{C} 23$ & & & & & & 1 & & & & & & & 1 \\
\hline $\mathrm{C} 24$ & & & & & & 1 & & & & & 1 & & 2 \\
\hline $\mathrm{C} 25$ & & & & & & 1 & & & & & & & 1 \\
\hline $\mathrm{C} 26$ & & & & & & 1 & & & & & & & 1 \\
\hline $\mathrm{C} 27$ & & & & & & 1 & & & & & & & 1 \\
\hline $\mathrm{C} 28$ & & & & & & 1 & & & & & & & 1 \\
\hline C29 & & & & & & & 1 & & & & & & 1 \\
\hline C30 & & & & & & & 1 & & & & & & 1 \\
\hline C31 & & & & & & & & 1 & & & & & 1 \\
\hline C32 & & & & & & & & 1 & & & & & 1 \\
\hline C33 & & & & & & & & & 1 & & & & 1 \\
\hline C34 & & & & & & & & & & 1 & & & 1 \\
\hline C35 & & & & & & & & & & & & 1 & 1 \\
\hline Total & 239 & 18 & 8 & 6 & 7 & 11 & 8 & 8 & 7 & 2 & 2 & 3 & 319 \\
\hline
\end{tabular}

* All abbreviations are given in Table 2 .

the phylogenetic relationship of 35 haplotypes of the cyt $b$ gene, on the basis of Kimura two-parameter distances (Figure 2). Four cyt $b$ sequences (GenBank Accession no. AF419237, EF061244, GU256940 and JN117614) from Zebu (B. indicus) were used together and B. javanicus was used as the outgroup (GenBank Accession no. D82889). The reliability of the tree topology was assessed by 1,000 bootstrap replications. The tree was divided into two distinct genetic lineages, B. taurus and B. indicus. Three (C18, C19 and C25) of 35 haplotypes belonged to $B$. indicus lineage and these haplotypes contained four Chinese breeds (Bohai black, Kazakh, Qinchuan and
Jinnan). Cai et al. (2007) reported that 14 Chinese cattle breeds, including these four breeds, were of a mixture of two cattle lineages, B. taurus and B. indicus. Clade I consisted of haplotypes that derived from all breeds. Clades II-IV were found only in Asian breeds and contained C1 haplotype. Clades III and IV contained Chikso and Chinese breeds. The Chikso breed was classified as being of $B$. taurus lineage and extended to Clade I-III. The existence of a $B$. indicus lineage for Korean cattle breeds has not been found (Kikkawa et al., 2003; Kim et al., 2003; Mannen et al., 2004), and all Chikso individuals used in this study were verified as being of $B$. taurus lineage. 


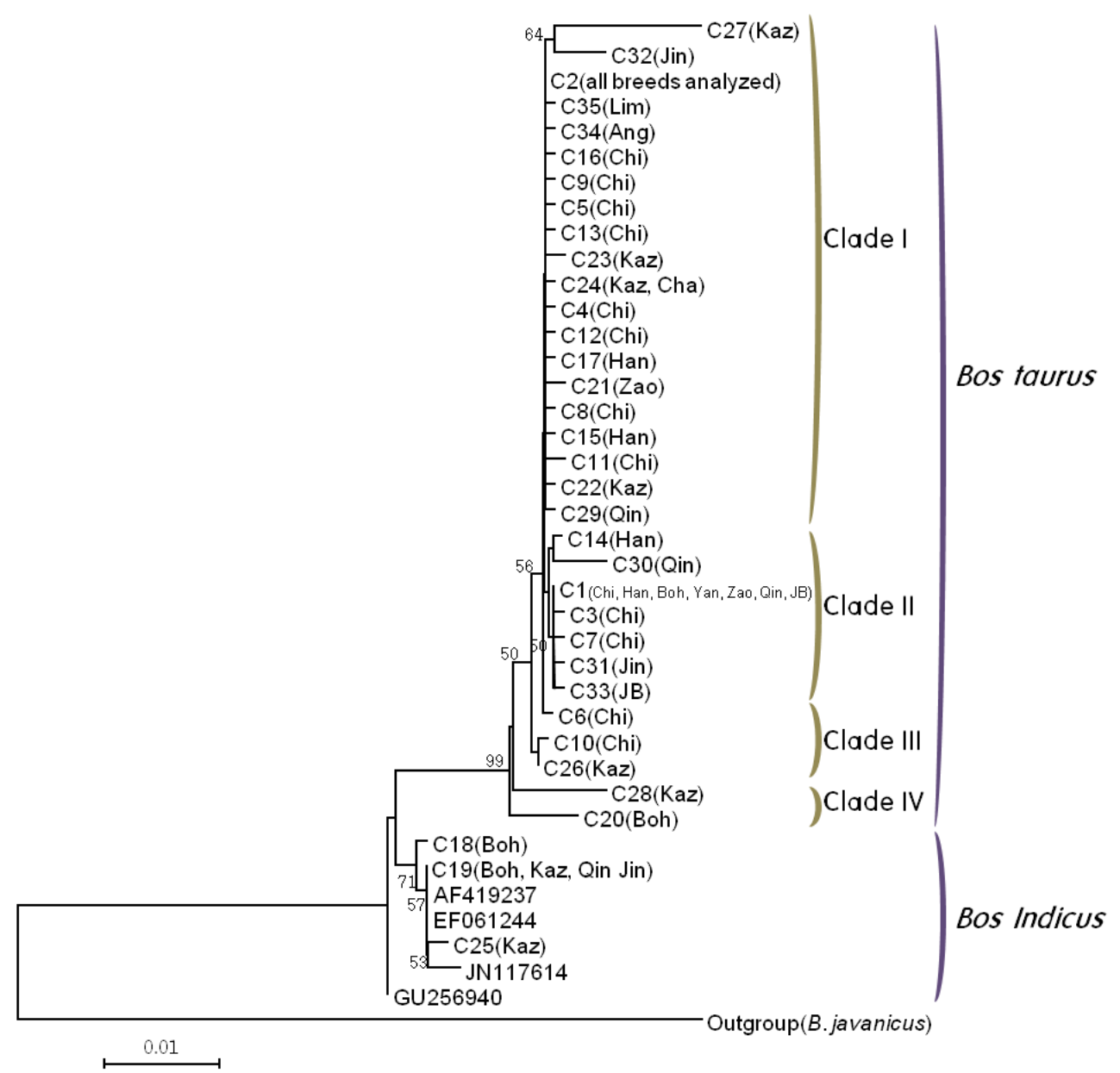

Figure 2. Phylogenetic relationship among 35 haplotypes of the cyt $b$ gene from Asian and European cattle breeds. The tree was constructed with the neighbor-joining method (Saitou and Nei, 1987) on the basis of Kimura 2-parameter distances. B. javanicus was used as the outgroup (GenBank accession no. D82889). The numbers at branches stand for bootstrap values higher than $50 \%$ out of 1,000 replications. The bar scale indicates genetic distance. Abbreviations for population or breed are the same as those in Table 2.

For verification of the phylogenetic status of the Chikso breed, a NJ tree was reconstructed based on Dxy genetic distances among Asian and European breeds (Figure 3). Four Chinese breeds, Bohai black, Jinnan, Qinchuan, Kazahk, were located in between B. taurus and B. indicus lineage. In the NJ tree based on 35 haplotypes (Figure 2), these breeds were verified to have two mtDNA maternal lineages, B. taurus and B. indicus. The phylogenetic location of these breeds was estimated to be due to these characteristics. Asian breeds and European breeds formed two independent groups in B. taurus lineage. Korean breeds, Chikso and Korean brown and Japanese black were located to the end of the tree through Chinese and European breeds from $B$. indicus. In the genetic distances estimated for verification of the genetic relationship between Chikso and other breeds, Chikso was more closely related to Yanbian (0.00040) than to Zaosheng (0.00064), Korean brown (0.00066) or JB (0.00066) (Table 4). These two Chinese breeds are distributed in north China (Cai et al., 2007). Yanbian breed samples were collected from Yanji City, which is the closest to the Korean peninsula. These results suggest that Korean cattle breeds might have been introduced from north China. This notion agrees with a report by Jia et al. (2010) that analyzed haplogroup patterns using mtDNA D-loop sequence.

Up until now, Chikso and Korean brown were classified as individual breeds on the sole basis of their coat color, however, there was no molecular genetic evidence. In this study, the Chikso breed was determined to be genetically closer to Yanbian and Zaosheng breeds than to the Korean brown breed in terms of phylogenetic analysis, although genetic distances showed slightly differing results. This result suggests that Chikso and Korean brown have a genetic difference based on their mtDNA cyt $b$ gene, as well as based on their coat color for classification as breed.

In this study, we determined the full-length coding sequences of mtDNA cyt $b$ gene and analyzed the genetic relationship and phylogenetic status of the Chikso breed. The Chikso breed was classified into B. taurus lineage and was found to be genetically more closely related to two 


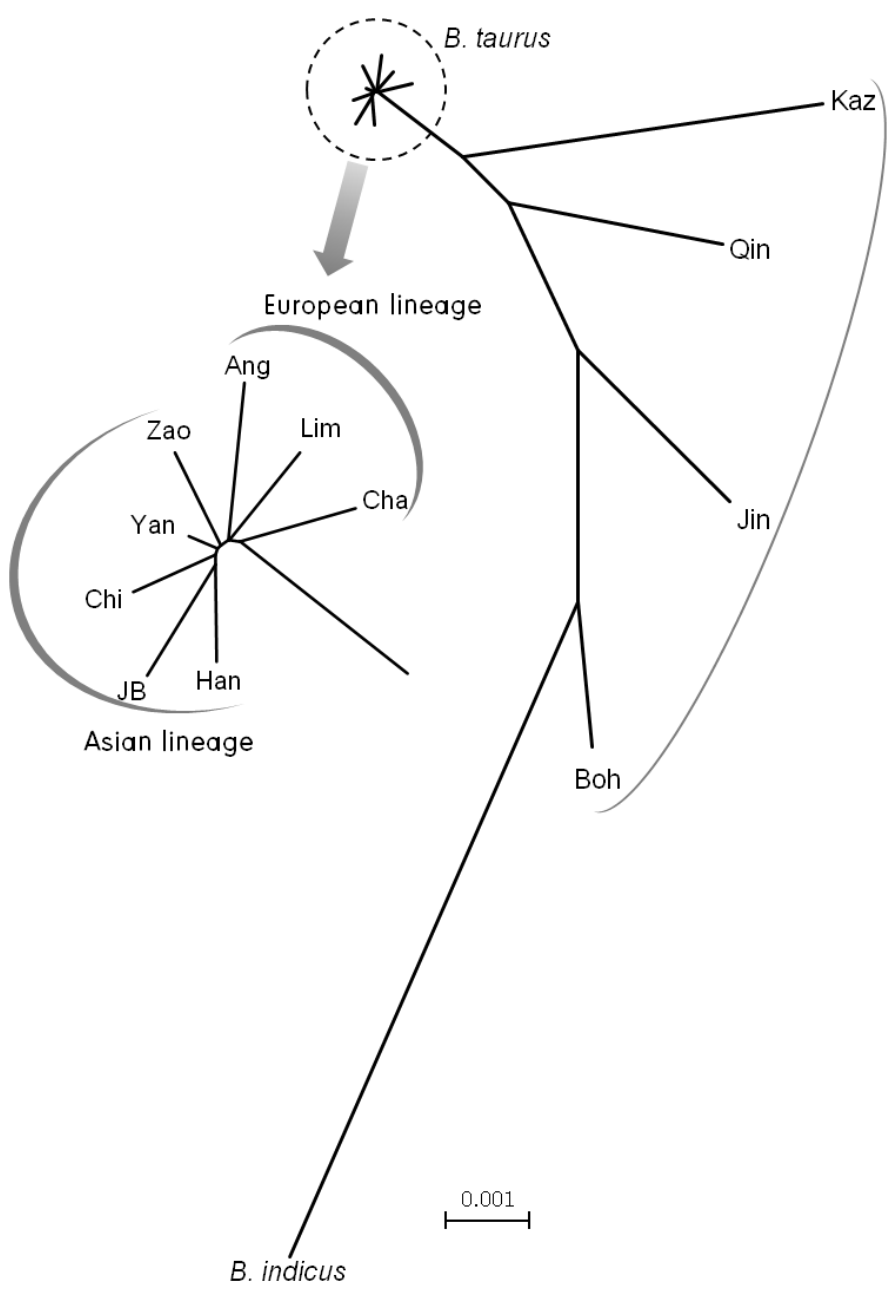

Figure 3. Phylogenetic relationship among 12 cattle breeds of B. taurus lineage and a breed of B. indicus lineage (GenBank accession no. JN117614-5). The tree was constructed with the neighbor-joining method (Saitou and Nei, 1987) on the basis of Dxy distances. The bar scale indicates genetic distance. Abbreviations for population or breed are the same as those in Table 2 .

Chinese breeds than to the Korean brown. For more detailed phylogenetic analysis and genetic characterization of the Chikso breed, additional genetic markers (e.g., mtDNA Korea.

Table 4. Dxy genetic distances among 12 cattle breeds and based on mtDNA cyt $b$ gene sequences

\begin{tabular}{|c|c|c|c|c|c|c|c|c|c|c|c|c|c|}
\hline & Chi & Han & Boh & Yan & Zao & Kaz & Qin & Jin & $\mathrm{JB}$ & Ang & Cha & Lim & Zebu \\
\hline Chi & - & & & & & & & & & & & & \\
\hline Han & 0.00065 & - & & & & & & & & & & & \\
\hline Boh & 0.00889 & 0.00904 & - & & & & & & & & & & \\
\hline Yan & 0.00040 & 0.00050 & 0.00877 & - & & & & & & & & & \\
\hline Zao & 0.00064 & 0.00074 & 0.00901 & 0.00048 & - & & & & & & & & \\
\hline Kaz & 0.00595 & 0.00609 & 0.01099 & 0.00581 & 0.00604 & - & & & & & & & \\
\hline Qin & 0.00485 & 0.00497 & 0.00938 & 0.00471 & 0.00495 & 0.00865 & - & & & & & & \\
\hline Jin & 0.00671 & 0.00685 & 0.00935 & 0.00658 & 0.00681 & 0.00972 & 0.00825 & - & & & & & \\
\hline JB & 0.00066 & 0.00073 & 0.00907 & 0.00052 & 0.00077 & 0.00616 & 0.00501 & 0.00688 & - & & & & \\
\hline Ang & 0.00075 & 0.00088 & 0.00910 & 0.00058 & 0.00081 & 0.00610 & 0.00504 & 0.00691 & 0.00094 & - & & & \\
\hline Cha & 0.00075 & 0.00088 & 0.00910 & 0.00058 & 0.00081 & 0.00602 & 0.00504 & 0.00691 & 0.00094 & 0.00088 & - & & \\
\hline Lim & 0.00060 & 0.00073 & 0.00895 & 0.00044 & 0.00067 & 0.00595 & 0.00490 & 0.00676 & 0.00079 & 0.00073 & 0.00073 & - & \\
\hline Zebu & 0.01673 & 0.01693 & 0.01033 & 0.01664 & 0.01687 & 0.01596 & 0.01390 & 0.01217 & 0.01699 & 0.01693 & 0.01693 & 0.01678 & - \\
\hline
\end{tabular}

\footnotetext{
* All abbreviations are given in Table 2 .
} 


\section{ACKNOWLEDGEMENTS}

This work received grant support from the Agenda Program (no. PJ008431012012), Rural Development Administration, Republic of Korea.

\section{REFERENCES}

Anderson, S., M. H. de Bruijn, A. R. Coulson, I. C. Eperon, F. Sanger and G. I. Young. 1982. Complete sequence of bovine mitochondrial DNA. Conserved features of the mammalian mitochondrial genome. J. Mol. Biol. 156:683-717.

Berthouly, C., J. C. Maillard, L. Pham Doan, T. Nhu Van, B. Bed'Hom, G. Leroy, H. Hoang Thanh, D. Laloe, N. Bruneau, C. Vu Chi, V. Nguyen Dang, E. Verrier and X. Rognon. 2010. Revealing fine scale subpopulation structure in the Vietnamese H'mong cattle breed for conservation purposes. BMC Genet. 11:45.

Bradley, D. G., D. E. MacHugh, P. Cunningham and R. T. Loftus. 1996. Mitochondrial diversity and the origins of African and European cattle. Proc. Natl. Acad. Sci. USA. 93:5131-5135.

Bradley, D. G. and D. A. Magee. 2006. Genetics and the origins of domestic cattle. In: Documenting domestication: new genetic and archaeological paradigms (Ed. M. A. Zeder, D. G. Bradley, E. Emshwiller and B. D. Smith). London: University of California Press. pp. 317-328.

Bruford, M. W., D. G. Bradley and G. Luikart. 2003. DNA markers reveal the complexity of livestock domestication. Nat. Rev. Genet. 4:900-910.

Cai, X., H. Chen, C. Lei, S. Wang, K. Xue and B. Zhang. 2007. mtDNA diversity and genetic lineages of eighteen cattle breeds from Bos taurus and Bos indicus in China. Genetica 131:175183.

FAO (Food and Agriculture Organization of the United Nations). 2007a. Global plan of action for animal genetic resources and the interlaken declaration. available at http://www.fao.org/ docrep/010/a1404e/a1404e00.htm.

FAO. 2007b. The State of the World's Animal Genetic Resources for Food and Agriculture. FAO, Rome.

Felsenstein, J. 1985. Confidence limits on phylogenies: an approach using the bootstrap. Evolution 39:783-791.

Hall, S. J. G. and D. G. Bradley. 1995. Conserving livestock breed biodiversity. Trends Ecol. Evol. 10:267-270.

Helmer, D., L. Gourichon, H. Monchot, J. Peters and M. S. Segui. 2005. Identifying early domestic cattle from Pre-Pottery Neolithic sites on the Midddle Euphrates using sexual dimorphism. In: The first steps of animal domestication: new archaeozoological approaches (Ed. J-D. Vigne, J. Peters and D. Helmer). Oxford: Oxbow. pp. 86-95.

Irwin, D. M., T. D., Kocher and A. C. Wilson. 1991. Evolution of the cytochrome b gene of mammals. J. Mol. Evol. 32:128-144.

Jia, S., Y. Zhou, C. Lei, R. Yao, Z. Zhang, X. Fang and H. Chen. 2010. A new insight into cattle's maternal origin in six Asian countries. J. Genet. Genomics 37:173-180.

Kikkawa, Y., T. Takada, Sutopo, K. Nomura, T. Namikawa, H. Yonekawa and T. Amano. 2003. Phylogenies using mtDNA and SRY provide evidence for male-mediated introgression in Asian domestic cattle. Anim. Genet. 34:96-101.
Kim, K. I., J. H. Lee, S. S. Lee and Y. H. Yang. 2003 Phylogenetic relationships of Northeast Asian cattle to other cattle populations determined using mitochondrial DNA D-Loop sequence polymorphism. Biochem. Genet. 41:91-98.

Lau, C. H., R. D. Drinkwater, K, Yusoff, S. G. Tan, D. J. S. Hetzel and J. S. F. Barker. 1998. Genetic diversity of Asian water buffalo (Bubalus bubalis): mitochondrial DNA D-loop and cytochrome b sequence variation. Anim. Genet. 29:253-264.

Librado, P. and J. Rozas. 2009. DnaSP v5: a software for comprehensive analysis of DNA polymorphism data. Bioinformatics 25:1451-1452.

MacHugh, D. E., R. T. Loftus, P. Cunningham and D. G. Bradley. 1998. Genetic structure of seven European cattle breeds assessed using 20 microsatellite markers. Anim. Genet. 29:333-40.

Mannen, H., M. Kohno, Y. Nagata, S. Tsuji, D. G. Bradley, J. S. Yeo, D. Nyamsamba, Y. Zagdsuren, M. Yokohama, K. Nomura and T. Amano. 2004. Independent mitochondrial origin and historical genetic differentiation in North Eastern Asian cattle. Mol. Phylogenet. Evol. 32:539-544.

Martín-Burriel, I., C. Rodellar, J. Cañón, O. Cortés, S. Dunner, V. Landi, A. Martínez-Martínez, L. T. Gama, C. Ginja, M. C. T. Penedo, A. Sanz, P. Zaragoza and J. V. Delgado. 2011. Genetic diversity, structure, and breed relationships in Iberian cattle. J. Anim. Sci. 89:893-906.

Miller, S. A., D. D. Dykes and H. F. Polesky. 1988. A simple salting out procedure for extracting DNA from human nucleated cells. Nucleic Acids Res. 16:1215.

Pesole, G., C. Gissi, A. de Chirica and C. Saccone. 1999. Nucleotide substitution rate of mammalian mitochondria genomes. J. Mol. Evol. 48:427-434.

Ruane, J. 2000. A framework for prioritizing domestic animal breeds for conservation purposes at the national level: a Norwegian case study. Conserv. Biol. 14:1385-1393.

Saitou, N. and M. Nei. 1987. The neighbor-joining method: A new method for reconstructing phylogenetic trees. Mol. Biol. Evol. 4:406-425.

Simianer, H. 2005. Decision making in livestock conservation. Ecol. Econ. 53:559-572.

Souza, C. A., S. R. Paiva, R. W. Pereira, S. E. Guimarães, W. M. Jr Dutra, L. S. Murata and A. S. Mariante. 2009. Iberian origin of Brazilian local pig breeds based on Cytochrome b (MT-CYT) sequence. Anim. Genet. 40:759-762.

Stock, F., C. J. Edwards, R. Bollongino, E. K. Finlay, J. Burger and D. G. Bradley. 2009. Cytochrome $b$ sequences of ancient cattle and wild ox support phylogenetic complexity in the ancient and modern bovine populations. Anim. Genet. 40:694700.

Sultana, S., H. Mannen and S. Tsuji. 2003. Mitochondrial DNA diversity of Pakistani goats. Anim. Genet. 34:417-421.

Tamura, K., D. Peterson, N. Peterson, G. Stecher, M. Nei and S. Kumar. 2011. MEGA5: molecular evolutionary genetic analysis using maximum likelihood evolutionary distance, and maximum parsimony methods. Mol. Biol. Evol. 28:2731-2739.

Thompson, J. D., D. G. Higgins and T. I. Gibson. 1994. CLUSTAL W: improving the sensitivity of progressive multiple sequence alignment through sequence weighting, position-specific gap penalties and weight matrix choice. Nucl. Acids Res. 22:46734680 . 
Toro, M. and A. Caballero. 2005. Characterization and conservation of genetic diversity in subdivided populations. Philos. Trans. R. Soc. Lond. B Biol. Sci. 360:1367-1378.

Troy, C. S., D. E. MacHugh, J. F. Bailey, D. A. Magee, R. T. Loftus, P. Cunningham, A. T. Chamberlain, B. C. Sykes and D. G. Bradley. 2001. Genetic evidence for Near-Eastern origins of European cattle. Nature 410:1088-1091.
Yap, F. C., Y. J. Yan, K. T. Loon, J. L. Zhen, N. W. Kamau and J. V. Kumaran. 2010. Phylogenetic analysis of different breeds of domestic chickens in selected area of Peninsular Malaysia inferred from partial cytochrome $b$ gene information and RAPD markers. Anim. Biotechnol. 21:226-240. 